\title{
Identification of the Phillips Curve Trade-Off Phenomenon in Indonesia, Using the Generalized Method of Moments Approach
}

\author{
Ginanjar Syamsuar*, Sumitro Sumitro \\ Department of Management \\ Sekolah Tinggi Ilmu Ekonomi Indonesia \\ Jakarta, Indonesia \\ *ginanjar.syamsuar@stei.ac.id
}

\begin{abstract}
This study aims to identify the existence of the phenomena of the Phillips Indonesia curve trade-off in the period 1970 - 2018 using the analytical approach modelling Generalized Method of Moments (GMM). With respect to secondary data for 49 years (quarterly data), namely the variable inflation rate, unemployment rate, potential output and output gap analysed, it is found that the phenomena of the Phillips curve trade-off occurred in Indonesia, namely the existence and pattern of the curve showed a change in almost every time, in accordance with changes in economic structure, especially those caused by the economic crisis. Between the two observations periods, namely the period before the crisis and after the crisis, the format of expectation formation and Phillips curve were significantly different. Before-crisis the influence of output-gap on changes in the development of inflation variables tends to be moderate and the dominance of the expectation formation format is backward and forward looking relatively balanced, whereas after-crisis the effect of output-gap pressure on inflation development tends to increase and the dominance of the expectation formation format is forward looking.
\end{abstract}

Keywords: Phillips curve trade-off, Generalized Method of Moments (GMM), backward-looking, forward-looking

\section{INTRODUCTION}

Inflation and unemployment are the two main economic problems that are often faced by the people of a country. The purpose of developing countries is for the welfare of the people, hence the problem of high unemployment is a condition that is not desired by any country. If the problem of inflation and unemployment is not controlled, then both of these problems can have adverse effects to the economic, social, political and environmental and cultural. To avoid the various adverse effects that may be caused by both of these problems, a macroeconomic policy is needed in a comprehensive macro policy. In the Phillips curve theory concept, high unemployment will indeed tend to reduce inflation [1]. But what's interesting in Indonesia is a phenomenon that often occurs is when unemployment is high, the inflation rate also remains high. In fact, the goal that is always desired for both problems are low.
Phillips research that uses data on the rate of change in wages and unemployment in England during the years 18611913, shows that if there is inflation reflected by an increase in high wage rates will be able to cause a decrease in the unemployment rate. Conversely, a high unemployment rate will be accompanied by a decrease in the wage rate (wages become low) [1].

Similarly, some studies about the existence of the Phillips curve in Indonesia have been carried out by using a different approach and produce results that vary. Generally, this approach, aside from being a macro approach that uses aggregate data and a traditional hypothesis approach, also has not addressed the main issues above as a whole, particularly related to changes in Indonesia's economic fundamentals after the 1997 economic crisis. Meanwhile, in the perspective of policy implementation, especially monetary policy by Bank of Indonesia, the existence of the Phillips curve is more fully believed to be "exogenous", namely that inflation control policies will have an impact on declining economic growth, and vice versa. In line with the direction of monetary policy going forward which tends to lead to the implementation of an inflation targeting framework, the validity of these beliefs needs to be further tested [2].

The shape of the Phillips curve has a downward slope, which shows a negative relationship between changes in the wage level and the unemployment rate, i.e. when the wage level rises, unemployment is low, or vice versa. The Phillips curve proves that price stability and high employment opportunities cannot occur simultaneously, which means that if you want to achieve high employment opportunities the unemployment rate is low, as a consequence one must be willing to bear the burden of high inflation. However, based on the results of research conducted in the Bureau of Budget Analysis and Implementation of the State Budget - DPRRI with Indonesian inflation and unemployment data from 1976 to 2006 shows that in Indonesia the relationship between inflation and unemployment is no longer a trade-off but rather a tradeoff going in the same direction, its mean that high inflation is also followed by high unemployment, or has a positive relationship between unemployment and inflation [3]. So that the relationship between changes in the unemployment rate 
based on the results and recommendations of previous studies

with inflation in Indonesia deviates from the Phillips curve theory. Another reason is that the Phillips curve only happens in the short run but not in the long run. Because in the short run the sticky price still applies while in the long run the flexible price applies [3]. In other words, unemployment will return to its natural level so that the relationship between inflation and unemployment will be positive.

In the context of multivariate relations where the nature of the relationship between output growth and inflation is basically very complex. This is likely due to the varied patterns of interaction and mutual influence between the determinants of inflation and the determinants of output growth. An understanding can be drawn that, even if a close relationship between inflation and output growth occurs, the relationship will tend to be complex, more than just a relationship of two variables that are linear and monotonic.

The above background is the issue that is more grounded in the findings of Laxton et al. [4], concerning the asymmetry of the effect of economic activity on inflation in the seven main OECD countries, provides an important conclusion, namely that there is no trade-off between economic activity and inflation in the long run [4]. These findings also imply that there is strong evidence that the Phillips curve is not linear. The nonlinearity is reflected in the strong influence of excess demand shocks in driving inflation shocks of the excess supply in dampening inflation. Strong evidence of the existence of nonlinearities Phillips curve is also found in Clark's research, Debelle and Laxton [5], and Fischer [6].

Based on the fact the results of the analysis conducted by researchers earlier, the purpose of this study was to identify the phenomenon of the Phillips curve trade-off in Indonesia using Generalized Method of Moments (GMM) model analysis approach. In particular, which is also observed is the possibility of changing the behaviour of the Phillips curve in response to changing macroeconomic fundamentals.

\section{METHODS}

\section{A. Data}

The data used in this study include: (1) inflation measured using the Consumer Price Index (CPI), (2) Output level, measured using real Gross Domestic Product (GDP), and (3) Potential Output and Output gap, which is measured by using several alternative univariate methods, such as HodrickPrescott (HP)-Filter, Unobserved Component (UC), and Unobserved Components with the Markov-Switching process. In general, these data are secondary data and are sourced from the Central Statistics Agency (BPS), Bank Indonesia (BI), and other sources.

\section{B. Model Specifications and Research Design}

In this study, constructed a model to estimate inflation generated by the independent variables: unemployment, output gap, and inflation lag good-looking or backward- and forwardlooking for the purpose of identifying and analysing the existence of the Phillips curve trade-off. The model proposed for estimation and analysis of the Phillips curve trade-off is conducted by several researchers as a reference, the model gives different results on the existence of Phillips curve tradeoffs according to the time period used, however on this research occasion besides the data period to be used longer/newer there is also the addition of econometric statistical analysis which in previous studies was not done.

The model to be estimated and analysed is a model with a dynamic panel method that is the Generalized Method of Moments (GMM) model. The GMM approach is a popular one because GMM is a common estimator and provides a more useful framework for comparison and assessment and provides a simple alternative to other estimators, especially towards maximum likelihood.

\section{GMM Modeling and Analysis Procedures}

To estimate the dynamic panel data model parameters in the equation will be used method Arrelano-Bond Generalized Method of Moments (AB-GMM). From the AB-GMM estimation results, it is then seen whether the instruments used are valid. If not, then use the SYS-GMM approach to address the validity of the instrument on the AB-GMM approach. To test the validity of the instrument in the AB-GMM approach, the Sargan test can be used. The Sargan Test for over identifying restriction is an approach to detect whether there is a problem with the validity of the instrument. The hypothesis for this test states that there is no problem with the validity of the instrument in the sense that such instruments are not correlated with the error in the equation AB-GMM. Sargan's statistical value is calculated as:

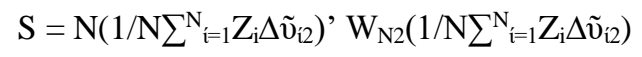

Under the null hypothesis condition, the statistical value above has a Chi-square $\chi_{q}^{2}$ distribution, with q stating the number of instruments minus the number of parameters used in the model.

To see the consistency of the estimation results generated from the AB-GMM model an autocorrelation test will be performed using Arellano-Bond statistics $m_{1}$ and $m_{2}$. This consistency is shown by the significant statistical value of $m_{1}$ and the statistical value of $m_{2}$ which is not significant. [7]. After testing the validity of the instrument using the Sargan test and the Arellano-Bond $m_{1}$ and $m_{2}$ tests to see the consistency of the estimators obtained, the model is used to interpret the results.

In addition to the selection and comparison of models, the results obtained will also be tested for significance levels as well as signs of each estimated coefficient obtained. The estimated coefficient sign is then analysed whether it is relevant to the existing theory. From the estimation results of the two approaches will be further analysed to answer the research hypothesis.

The construct of the Phillips curve model to be tested for existence is: 


$$
\pi=\pi^{\mathrm{e}}-\beta\left(\mathrm{u}-\mathrm{u}^{\mathrm{n}}\right)+v
$$

Which is estimated using the output gap approach as follows:

$$
\pi_{\mathrm{t}}=\mu+\gamma_{1} \pi_{\mathrm{t}-1}+\delta_{\mathrm{i}} \mathrm{Y}_{\text {gap t-1 }}+\varepsilon_{\mathrm{t}}
$$

Where $\mu$ is constant, and $\gamma_{1}>0$

If $\delta_{i}>0$, then the existence of the Phillips Curve is valid, in the sense that there is a significant positive relationship between inflation and the output gap.

So the statistical hypothesis is as follows:

- H1: $\rho \mathrm{ij}=\rho \mathrm{ij}$ \{ unemployment does not affect inflation or inflation does not affect unemployment $\}$.

- H2: $\rho \mathrm{ij}=\rho \mathrm{ji}$ \{unemployment and inflation affect each other or unemployment and inflation do not affect each other\}.

- H3: $\delta_{\mathrm{i}} \leq 0$ \{GMM estimation model (generalized method of moments) The Phillips curve trade-off is invalid\}.

\section{RESUlTS AND DISCUSSION}

\section{A. Granger Casuality Testing}

The results of the Granger causality test are shown in table I. found that inflation (INF) statistically and significantly affects unemployment (UNP). This can be seen from the probability value smaller than 0.05 which is equal to 0.0009 . While unemployment (UNP) statistically does not significantly affect inflation (INF), this can be seen from the probability value greater than 0.05 which is equal to 0.0781 . Thus, it is concluded that there is unidirectional causality between inflation (INF) and unemployment (UNP) variables, namely only inflation (INF) which statistically significantly influences unemployment (UNP) and does not apply otherwise at the 5\% significance level.

TABLE I. GRANGER CAUSALITy TEST RESUlts

\begin{tabular}{|l|l|l|l|}
\hline \multicolumn{1}{|c|}{ Null Hypothesis: } & Obs. & F - Statistic & Probability \\
\hline $\begin{array}{l}\text { INF does not Granger Cause } \\
\text { UNP }\end{array}$ & \multirow{2}{*}{168} & 11.9481 & 0.0009 \\
\cline { 1 - 1 } $\begin{array}{l}\text { UNP does not Granger Cause } \\
\text { INF }\end{array}$ & & 3.08329 & 0.0781 \\
\hline
\end{tabular}

At the $10 \%$ significance level, the Granger causality test results in the table indicate a two-way causality between the inflation (INF) and unemployment (UNP) variables. Inflation (INF) statistically and significantly affects unemployment (UNP). This can be seen from the probability value smaller than 0.10 which is equal to 0.0009 . Whereas unemployment (UNP) statistically and significantly influences inflation (INF). This can be seen from the probability value that is smaller than 0.1 which is equal to 0.0781 .

\section{B. Output Gap Measurement}

The study of macroeconomic fluctuations distinguishes between short-run fluctuations who cyclical; and long-run developments that reflect the basic behaviour of output. In this context, the method of estimating potential output used is univariate and multivariate methods that take into account the developments of other macroeconomic variables, so that the estimation of potential output can be considered close to concept of economic capacity or sustainable aggregate supply.

1) Output gap estimation: Based on the three proposed output gap techniques / methods, the results of estimating the output gap are calculated according to the method, namely according to the unobserved component model (UCM) technique, according to the unobserved component-Markov switching model (UCMS), and according Hodrick-Prescott filter (HPF).

The statistical calculation results for each estimated output gap are as follows.

TABLE II. OUTPUT GAP ESTIMATION RESUlTS

All observations (1970.1-2018.4)
\begin{tabular}{|l|l|l|l|}
\hline \hline \multicolumn{1}{|c|}{ UCM } & UCMS & HPF \\
\hline Mean & -0.000850 & -0.001365 & -0.000002 \\
\hline Standard deviation & 0.022023 & 0.020630 & 0.023437 \\
\hline F-test for Equal Variances (HO: Equal Variances) & \\
\hline UCM & & & \\
\hline UCMS & $2,73(0,00)$ & & \\
\hline HPF & $6,15(0,00)$ & $2,73(0,00)$ & \\
\hline \hline
\end{tabular}

\begin{tabular}{|c|c|c|c|}
\hline & 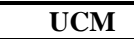 & UCMS & HPF \\
\hline Mean & -0.000096 & -0.001023 & -0.002421 \\
\hline Standard deviation & 0.011673 & 0.0220017 & 0.031403 \\
\hline \multicolumn{4}{|c|}{ F-test for Equal Variances (HO: Equal Variances) } \\
\hline UCM & & & \\
\hline UCMS & $3,01(0,00)$ & & \\
\hline HPF & $6,14(0,00)$ & $1,62(0,00)$ & \\
\hline
\end{tabular}

Pre-crisis (1980.1-1997.2)

\begin{tabular}{|c|c|c|c|}
\hline & UCM & UCMS & HPF \\
\hline Mean & $-0,005328$ & $-0,010790$ & $-0,010833$ \\
\hline Standard deviation & 0,012940 & 0,014015 & 0,050516 \\
\hline \multicolumn{4}{|c|}{ F-test for Equal Variances (HO: Equal Variances) } \\
\hline UCM & & & \\
\hline UCMS & $1,11(0,73)$ & & \\
\hline HPF & $13,23(0,00)$ & $12,45(0,00)$ & \\
\hline
\end{tabular}

Post-crisis (1997.3-2018.4)

From table II. It can be concluded two things, namely:

- The average value of the estimated output gap generally increases during the crisis period,

- The variance value of each estimated output gap is different, except in the crisis period, where UCM and UCMS have variances same.

2) Linear and dynamic correlation of estimated output gap: The results of calculating the linear correlation coefficient between the estimated output gap can be concluded two things, that are: (1) there is a significant correlation between the estimated output gap, and (2) the level of the 
influence of each independent variable. Obtaining the estimated results using quarterly data on several different periods is summarized in table III.

Obtaining the estimation results in the table identified that overall the model can explain the behaviour of the Phillips curve according to the traditional Phillips curve version. In addition to the influence of independent variables that are significant at the 5\% level, the residual test shows that residual behaviour does not contain autocorrelation. Overall (all observations), the regression parameters of the inflation lag, backward looking parameters (0.62) and output gap (0.21) are very significant.

TABLE III. TEST RESUlts FOR THE EXISTENCE OF THE PHILlIPS CURVE stage: Simultaneous testing between existence, forms of expectations, and the linearity of the model. Taking into account the degree of complexity of the Phillips curve phenomenon, the existence test is a test of the minimum requirements that must be met. To test for the existence of the model used the traditional Phillips Curve hypothesis (Augmented Phillips Curve). Implicitly, the design of the model that takes into account the past value of inflation implies that the behaviour of the Phillips Curve is backward-looking.

The degree of complexity that is higher than the Phillips Curve phenomenon is examined by looking at how the pattern of the formation of market expectations as a whole, whether backward-looking, forward-looking, or both. To test this the new Phillips curve hypothesis model (hybrid model) is used. Furthermore, the highest degree of complexity of the Phillips Curve phenomenon is examined by looking not only at the existence and pattern of the formation of whole market expectations, but also on the possibility that the behaviour of the Phillips Curve is non-linear/asymmetrical.

The testing framework is also complemented by comparing test results on different subsamples, namely in the period before and after the 1997 economic crisis (pre and post-crisis). Comparison of these results is necessary because of changes in economic fundamentals and the interrelationships between variables in the period after the 1997 crisis.

1) Test the existence of the phillips curve model: Test the existence of the Phillips curve model is done by estimating the model:

$$
\pi_{\mathrm{t}}=\mu+\gamma_{1} \pi_{\mathrm{t}-1}+\delta_{\mathrm{i}} \mathrm{Y}_{\text {gap t-1 }}+\varepsilon_{\mathrm{t}}
$$

where $\pi_{\mathrm{t}}=\mathrm{Ln}(\mathrm{CPI})$ is the inflation of the current period $(\mathrm{t})$, $\pi_{\mathrm{t}-1}$ is the inflation of one previous period, $\mathrm{Y}_{\text {gap } t-\mathrm{i}}$ is the output gap in the previous period, and $\varepsilon_{\mathrm{t}}$ is the residual.

According to the nature and characteristics of the classical linear regression model form basically, the shape of the model can be estimated by utilizing the Ordinary Least Square method. The impact of the output gap variable (in the logarithmic transformation of natural numbers) to the inflation variable is estimated by calculating the linkages between variables that have a lag length between 1 to 4 quarters. Furthermore, the best model selection criteria are based on the suitability of the magnitude and significance level of the

\begin{tabular}{|c|c|c|c|c|}
\hline Period & $\gamma$ & $\delta$ & $\mathbf{R}^{2}$ & $\begin{array}{c}\text { ARCH LM-test } \\
(*)\end{array}$ \\
\hline All observations & 0.615 & 0.208 & 0.436 & 0.443 \\
\hline (1970.1-2018.4) & $(8.839)$ & $(5.586)$ & & $(1)$ \\
\hline Pre-crisis & 0.324 & $0.272 * *$ & 0.136 & 0.281 \\
\hline$(1980.1-1997.2)$ & $(3.617)$ & $(1.827)$ & & (4) \\
\hline Post-crisis & 0.618 & 0.541 & 0.781 & 0.063 \\
\hline (1997.3-2018.4) & $(5.107)$ & $(4.995)$ & & (4) \\
\hline \multicolumn{5}{|c|}{$\begin{array}{l}\text { Notes: } \\
\text { The number in the brackets below each parameter is the t-statistic value } \\
\text { ARCH LM-test }(*) \text { is a residual test with an authoritative lag between } 1 \text { to } \\
4 \text { periods. Subscript i is the lag period of the effect of the output gap (HPF) } \\
\text { on inflation, which is about } 2 \text { periods. } \\
(* *) \text { parameters are estimated using an output gap based on the } \\
\text { unobserved component (UCM) method with the effect of a } 3 \text {-period lag. }\end{array}$} \\
\hline
\end{tabular}

Furthermore, from these results it can also be seen that the effect of the output gap on inflation has changed from 0.27 in the pre-crisis period to 0.54 in the post-crisis period. This shows that in the post crisis period there was an increase in the influence/pressure of real economic activities on price developments. In addition to causing an increase in the Phillips Curve slope, these changes also imply that in times of crisis the rigidity of price developments in response to the development of demand systems has decreased. Overall, these results conclude that the existence of the Phillips Curve in Indonesia with the hypothesis of forming backward-looking expectations is valid.

2) Test the existence and pattern of expectation formation: Phillips curve are carried out by estimating the model:

$$
\pi_{\mathrm{t}}=\gamma_{\mathrm{b}} \pi_{\mathrm{b}-1}+=\gamma_{\mathrm{f}} \pi_{\mathrm{t}+1}+\delta_{\mathrm{i}} \mathrm{Y}_{\text {gap t-1 }}+\varepsilon_{\mathrm{t}}^{\mathrm{e}}
$$

where $\pi_{t+1}$ is the realization of inflation in the coming period and $\varepsilon_{\mathrm{t}}^{\mathrm{e}}$ is the expectation error.

To estimate the model used is the Generalized Method of Moments (GMM). The instrumental variables used in the estimation are inflation (lag 1 and 2), changes in exchange rates factors, and constant. The existence and pattern formation expectations of the (lag 0 and 1), base money growth (lag 0 and 1), seasonal 
Based on the results of the assessment it can be seen that overall the model can explain the behaviour of the new version of the Phillips Curve. In addition to the influence of significant independent variables at level 10 , and even $5 \%$, the residual test shows that residual behaviour does not contain autocorrelation. Unlike the standard statistical forms used in evaluating models, for example R2, GMM calculates the $\mathrm{j}$ statistic value, which is the minimum value of the objective function. The j-statistics can be used to test hypotheses from GMM estimation results, including testing the validity of the use of instrumental variables that exceed the number of parameters estimated (over identifying restrictions). From the results of separate tests, it was concluded that the over identifying restrictions on the estimation of the model are valid.

Overall (all observations), both backward- and forwardlooking parameters and the output gap (0.22) are very statistically significant. It is seen that, based on the structure of the model above, the value of $\gamma \mathrm{f}$ is significantly greater than $\gamma \mathrm{b}$, which indicates the dominance of the New-Keynesian Phillips Curve in explaining the inflation process. In addition, the Wald parameter restriction test concludes that the number of backward- and forward-looking parameters is one. Furthermore, from these results it can also be seen that the effect of the output gap on inflation has changed, although not significantly, from 0.12 in the pre-crisis period to 0.14 in the post-crisis period. Overall, these results conclude that the existence of the Phillips Curve in Indonesia with the hypothesis of the formation of hybrid expectations is valid.

TABLE IV. TEST RESULTS FOR THE EXISTENCE AND FORMATION PATTERNS OF EXPECTATIONS

\begin{tabular}{|c|c|c|c|c|c|}
\hline \multicolumn{6}{|c|}{ All observations (1970.1-2018.4) } \\
\hline \multirow[b]{2}{*}{$\gamma_{\mathrm{b}}$} & \multirow[b]{2}{*}{$\gamma_{f}$} & \multirow[b]{2}{*}{$\delta$} & \multirow[b]{2}{*}{ J-stat } & Wald-test & \multirow{2}{*}{$\begin{array}{c}\text { ARCH LM-test } \\
(*)\end{array}$} \\
\hline & & & & $\gamma_{b}+\gamma_{f}=$ & \\
\hline 0.172 & 0.649 & 0.220 & 0.056 & 0.694 & 0.398 \\
\hline$(2.324)$ & $(7.191)$ & $(3.109)$ & & & (2) \\
\hline \multicolumn{6}{|c|}{ Pre-crisis (1980.1-1997.2) } \\
\hline 0.376 & 0.599 & 0.120 & 0.072 & 0.419 & 0.002 \\
\hline$(4.937)$ & $(7.440)$ & $(1.510)$ & & & (4) \\
\hline \multicolumn{6}{|c|}{ Post-crisis (1997.3-2018.4) } \\
\hline 0.324 & 0.536 & 0.140 & 0.291 & 0.002 & 0.403 \\
\hline$(5.519)$ & $(7.143)$ & $(1.848)$ & & & (4) \\
\hline \multicolumn{6}{|c|}{$\begin{array}{l}\text { Notes: } \\
\text { The number in the brackets below each parameter is the t-statistic value. } \\
\text { The J-statistic is the minimum value of an objective function. The Wald- } \\
\text { test is a parameter restriction test. ARCH LM-test }(*) \text { is a residual test with } \\
\text { an authoritative lag between } 1 \text { to } 4 \text { periods. Subscript i is the lag period of } \\
\text { the effect of the output gap (HPF) on inflation, which is about } 2 \text { periods. }\end{array}$} \\
\hline
\end{tabular}

3) Simultaneous testing between existence, forms of expectations, and the linearity of the model: Based on the "Generalized Method of Moments" estimation method and similar instrumental variables in the previous test, namely inflation variables (lag 1 and 2) and constant, it is found that the overall estimation results of the model can explain the behavior of the new version of the Phillips curve with linearity parameters. The results of the partial model estimation each show the existence of convex and concave partial non- linearity. However, from the estimation results of the "core model" it can be seen that, even though there is a parametric difference in values between $\alpha 1$ and $\alpha 2$, the results of the parameter boundary test reject the temporary assumption that $\alpha 1+\alpha 2=0$. So, it can be concluded that statistically, nonlinearity in Phillips curve is not proven.

Overall observations, both backward- and forward-looking parameters and output gaps are statistically very significant, so it can be concluded that the presence of no-linearity in the Phillips curve is less strongly proven.

\section{Interpretation of the Phenomena of the Phillips Curve Modeling Results}

From the results of estimation and testing of the empirical model, several important findings were obtained, including the conclusion that the Phillips Curve phenomenon exists in the Indonesian economy, where the existence and behaviour of these curves change from time to time, in line with changes in the fundamental structure of the economy, especially as a result from the 1997 economic crisis. Specifically, the pattern of expectations and linearity formation in the Phillips Curve experienced a significant difference (change) between the pre and post crisis periods. The characteristics of the Phillips Curve in the pre-crisis period are: (1) the effect of output gap pressure on inflation development tends to be moderate $(0.2-0.3)$, (2) the dominance of the pattern of formation of backward and forward looking expectations is relatively balanced, and (3) the pattern of relationships tends to be linear. Meanwhile, the characteristics of the Phillips Curve in the pre-crisis period are: (1) the effect of output gap pressure on inflation development tends to increase $(0.4-0.6),(2)$ the dominance of the pattern of formation of forward-looking expectations, and (3) the pattern of relationships tends to be non-linear (convex).

Some important implications that need to be considered relate to efforts to formulate a strategic framework of economic policy that specifically and can be directed at including their views summarized as follows.

The role of the pattern to form dominantly forward-looking expectations other than to backward views is a reflection of the perception of economic actors who tend to expect to remain high (potential) inflationary pressures in the future. This is in line with the level of persistence and uncertainty of output and the very high price development in Indonesia. In connection with empirical facts, the effectiveness of achieving the final monetary policy target with a price stability target will depend on the extent of the central bank's commitment (credibility) in seeking the development of low and stable inflation over a certain period of time.

The tendency of changes in output linkages and price developments in the crisis period, which is reflected in the nonlinearity of the Phillips curve in line with the temporary assumptions about capacity constraints, especially in the crisis period. In addition, this also implies the need for policy formulation that takes into account the stages in which economic conditions are located. This is related to the trend of decreasing/increasing cost of controlling inflation. Therefore, it is also necessary to set priorities for economic growth or reduce inflation. 


\section{REFERENCES}

The phenomenon of the Phillips curve exists in the Indonesian economy, where the existence and behaviour of the curve has changed from time to time, in line with changes in the structure of economic fundamentals, especially as a result of the 1997 economic crisis.

The characteristic of the Phillips curve in the period before the crisis was its the gap of output pressure affected the development of inflation which tended to be moderate, the format of the formation of expectations between backward and forward-looking views, its dominance was relatively balanced, and the form of relations identified tended to be linear. Meanwhile, the characteristics of the Phillips curve in the postcrisis period of pressured output have an effect on the development of inflation with an upward trend, the format of formation of expectations is predominantly forward-looking, and the form of the relationship identified tends to be nonlinear.

[1] A.W Phillips, "The Relation between Unemployment and the Rate of Change of Money Wage Rates in the United Kingdom, 1861-1957," Economica, New Series, vol. 25, no. 100, pp. 283-299, 1958.

[2] Solikin, "Kurva Phillips dan Perubahan Struktural di Indonesia: Keberadaan, Pola Pembentukan Ekspektasi dan Linieritas," Buletin Ekonomi Moneter dan Perbankan, Bank Indonesia, Jakarta, 2004.

[3] Biro Analisa Anggaran dan Pelaksanaan APBN - DPRRI, Analisis Keberadaan Tradeoff Inflasi dan Pengangguran Kurva Phillips di Indonesia, DPR-RI, Jakarta, 2014.

[4] P. Clark, Laxton, and Rose, "Asymmetry in the U.S. output-inflation nexus,” IMF Staff Papers, vol. 43, no. 10, pp. 216-251, 1996.

[5] G. Debelle and D. Laxton, "Is the Phillips Curve Really a Curve?: Some Evidence for Canda, the United Kingdom, and the United States," IMF Working Paper, no..111, 1996.

[6] S. Fischer, "Long-Term Contracting, Sticky Prices, and Monetary Policy," Journal of Monetary Economics, vol.3, pp. 3 17-323, 1977.

[7] M. Arrelano, Panel Data Econometrics, Oxford Scholarship Online, Print ISBN-13: 9780199245284. DOI:10.1093/0199245282.001.0001, 2003. 